\title{
ANALYSIS OF THE INFLUENCE OF BROMAZEPAM ON COGNITIVE PERFORMANCE THROUGH THE VISUAL EVOKED POTENTIAL (P300)
}

\author{
Fernanda Puga', Heloisa Veiga ${ }^{1}$, Maurício Cagy', \\ Kaleb McDowell ${ }^{3}$, Roberto Piedade ${ }^{4}$, Pedro Ribeiro ${ }^{5}$
}

\begin{abstract}
Benzodiazepines have been used in the pharmacological treatment of anxiety for over four decades. However, very few studies have combined bromazepam and event-related potentials (ERP). The present study aimed at investigating the modulatory effects of this drug on brain dynamics. Specifically, the effects of bromazepam ( $3 \mathrm{mg}$ ) on the P300 component of the ERP were tested in a double-blind experiment. The sample, consisting of 15 healthy subjects (7 male and 8 female), was submitted to a visual discrimination task, which employed the "oddball" paradigm. Electrophysiological (P300) and behavioral measures (stroop, digit span, and reaction time) were analyzed across three experimental conditions: placebo 1 , placebo 2, and bromazepam. Results suggest that the effects of bromazepam ( $3 \mathrm{mg})$ on cognitive processes are not apparent. In spite of what seems irrefutable in current literature, bromazepam did not produce evident effects on the behavioral and electrophysiological variables analyzed.
\end{abstract}

KEY WORDS: bromazepam, event-related potential, P300.

\begin{abstract}
Análise da influência do bromazepam na performance cognitiva atraves do potencial evocado visual (P300)

RESUMO - Benzodiazepínicos têm sido utilizados no tratamento farmacológico da ansiedade há mais de quatro décadas. No entanto, poucos estudos têm combinado bromazepam e potencial evocado relacionado a evento (PRE). O presente estudo teve por objetivo investigar os efeitos modulatórios desta droga na dinâmica cerebral. Especificamente, os efeitos de $3 \mathrm{mg}$ de bromazepam no componente P300 do PRE foram analisados em um experimento duplo-cego. A amostra consistiu de 15 sujeitos sadios (7 homens e $8 \mathrm{mu}$ Iheres), submetidos a uma tarefa de discriminação visual utilizando o paradigma "oddball". Medidas eletrofisiológicas (P300) e comportamentais (stroop, digit span, e tempo de reação) foram analisadas em três condições experimentais: placebo 1, placebo 2 e bromazepam. Os resultados sugerem que os efeitos de $3 \mathrm{mg}$ de bromazepam em processos cognitivos não são aparentes. Apesar do que parece irrefutável na literatura, o bromazepam não produziu efeitos evidentes nas variáveis comportamentais e eletrofisiológicas analisadas.
\end{abstract}

PALAVRAS-CHAVE: bromazepam, potencial evocado relacionado a evento, P300.

Benzodiazepines, such as bromazepam, have been used in the pharmacological treatment of anxiety since the early $60^{\prime} s^{1}$. The benzodiazepine family of depressants is used therapeutically to produce sedation, induce sleep, relieve anxiety and muscle spasms, and to prevent seizures. In general, benzodiazepines act as hypnotics in high doses, anxioly- tics in moderate doses, and sedatives in low doses. Their mechanism of action on the central nervous system is (CNS) believed to be related to their ability to enhance the activity of gamma aminobutyric acid (GABA), the major inhibitory neurotransmitter-4. Effects of oral doses of bromazepam on memory, psychomotor activity, reaction time and vig-

\footnotetext{
${ }^{1}$ Mestranda, Laboratório de Mapeamento Cerebral e Integração Sensório-Motora, Instituto de Psiquiatria (IPUB), Universidade Federal do Rio de Janeiro, Rio de Janeiro RJ, Brazil (UFRJ); ${ }^{2}$ D.Sc. em Engenharia Biomédica, COPPE, UFRJ; ${ }^{3}$ PhD, Department of Kinesiology

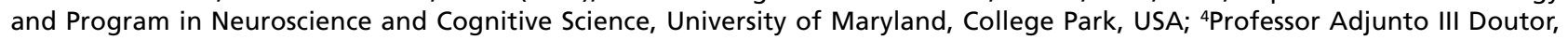
Coordenador do Laboratório de Mapeamento Cerebral e Integração Sensório-Motora, IPUB, UFRJ; ${ }^{5}$ Professor Adjunto II PhD, Escola de Educação Física e Desportos (EEFD), Laboratório de Mapeamento Cerebral e Integração Sensório-Motora, (IPUB), (UFRJ), Professor Pesquisador, Universidade Castelo Branco Rio de Janeiro RJ Brazil (PROCIMH-UCB).
}

Received 29 June 2004, received in final form 14 September 2004. Accepted 4 November 2004.

Dra. Fernanda Patrício Puga - Instituto de Psiquiatria, Laboratório de Mapeamento Cerebral e Integração Sensório-Motora, Uni versidade Federal do Rio de Janeiro - Avenida Venceslau Brás 71 Fundos - 22290-140 Rio de Janeiro RJ - Brasil. E-mail: fernandapuga@ globo.com 
ilance performance have been widely demonstrat$\mathrm{ed}^{5-8}$, Despite the vast number of vigilance studies that employed benzodiazepines, few have employed bromazepam and ERP measures ${ }^{9}$. Vigilance and selective attention must be engaged in the efficient processing of sensory information. The evoked p otential (EP) or event-related potential (ERP) has provided the means to examine the on-line processing of information during selective attention tasks. From a temporal perspective, the ERP has proved to be a successful tool to detect changes in neural activation yielded by specific drugs ${ }^{10-12}$. ERP parameters reflect detection-attention (N1), stimulus mismatch (P2, N2) and stimulus evaluation processes (P3) ${ }^{9}$. Specifically, the P3 (P300) component of the evoked potential has been the main focus of several experimental studies, since it has been closely related to various aspects of information processing ${ }^{13-17}$. P300 amplitude is a sensitive measure of the allocation of the subject's attentional resources during the task, and P300 latency has been suggested to index cognitive processing spe$\mathrm{ed}^{14}$. Studies have suggested that an increase in amplitude and a decrease in latency values indicate a superior cognitive performance ${ }^{16,18}$.

One of the few studies that examined the effects of bromazepam ( 6 and $12 \mathrm{mg}$ ) on the P300 component of the ERP in a visual vigilance task was conducted by Leeuwen et al. They observed smaller P300 amplitudes after the administration of the drug. Apparently, bromazepam deteriorates the ability of the individual to detect relevant information in the environment 9 .

Due to this, the present study aimed at investigating the modulatory effects of this drug on brain dynamics. To achieve this goal, the effects of bromazepam were analyzed through behavioral and electrophysiological measures. Specifically, the stroop and digit span tests were performed, subjects' reaction times were assessed, and a typical visual task was employed.

\section{METHOD}

Subjects - The sample consisted of 15 volunteers, 7 male and 8 female, with ages varying between 21 and 38 years ( $27 \pm 5$ years). All subjects were healthy, free of cognitive deficits and were not making use medication or any psychoactive or psychotropic substance at the time of the test. To assure that subjects did not present any impairment of their physical and mental health, and to identify and exclude from the experiment any subjects who could contaminate future results, a questionnaire was applied. The questionnaire also aimed to identify possible P300 biological determinants, such as food intake, body temperature, fatigue, drugs, among others. Subjects signed a consent form, where the experimental condition was thoroughly described. The experiment was submitted to the Psychiatric Institute's ethics committee for approval.

Study design and procedures - Subjects received a capsule (bromazepam or glucose) on three different occasions under a randomized, double-blind, crossover study. The procedures consisted of a three-day treatment: two of placebo (P1 and P2) and a day of bromazepam (B). The procedures were standardized in the following routine: 1) visual evoked potential; 2) Administration of capsule (bromazepam or placebo); 3) The second visual evoked potential, 20 minutes after drug ingestion; 4) Administration of the word color stroop test and the digit span test; 5) The third visual evoked potential, $60 \mathrm{mi}$ nutes after drug ingestion.

Visual evoked potential (P300) - A sound-attenuated room was prepared for data acquisition. Subjects were seated comfortably in a chair with armrest to minimize muscular artifacts. During the visual task, lights were turned off for subjects to concentrate exclusively on the monitor screen. A 15" Samsung monitor was placed in front of the individual. The visual stimulus was presented on the monitor by the ERP acquisition software, developed in DELPHI 5.0.

To elicit the P300, all subjects were submitted to the same visual discrimination task, which employed the "oddball" paradigm. In this paradigm, two stimuli are presented randomly, with one occurring infrequently ${ }^{18}$. The subjects were asked to discriminate target (infrequent) from non-target or standard stimuli (frequent). In the present experiment, target stimuli were represented by a square and non-target, by a circle. Subjects were instructed to respond to the target stimulus by pressing a button in a joystick (Model Quick Shot-Crystal CS4281).

Data acquisition - International 10/20 system ${ }^{19}$ for electroencephalography (EEG) electrode placement (referred to linked earlobes) was used with a 20-channel Braintech-3000 (EMSA-Medical Instruments, Brazil). The 19 monopolar electrodes were arranged in a nylon cap (ElectroCap Inc., Fairfax, VA, USA). Impedance for EEG and EOG electrodes were under $5 \mathrm{~K} \Omega$ and $20 \mathrm{~K} \Omega$, respectively. Visual inspection was employed for detection and elimination of artifacts. The data acquired had total amplitude of less than $100 \mu \mathrm{V}$. The signal was amplified with a gain of 22,000 . The EEG signals were acquired between 0.01 and $50 \mathrm{~Hz}$. Eye-movement (EOG) artifact was monitored with a bipolar electrode montage using two 9-mm diameter electrodes attached above and on the external canthus of the right eye. Moreover, independent component analysis (ICA) was applied to remove possible sources of artifacts. The EEG signal was ana- 
logically filtered between $0.01 \mathrm{~Hz}$ (high-pass) and 100 $\mathrm{Hz}$ (low-pass), and sampled at $240 \mathrm{~Hz}$. The software ERP Acquisition (Delphi 5.0), developed at the Brain Mapping and Sensorimotor Integration Lab, was employed with the following digital filters: Notch $(60 \mathrm{~Hz})$, high-pass of $0.3 \mathrm{~Hz}$ and low-pass of $25 \mathrm{~Hz}$.

Average processing - The program Average (MATLAB 5.3), which implements filter and epoch selection routines, was used to process acquired data. After data were acquired and stored, the average software loaded the data and established different routines. Specific filters were set up: a high-pass filter of $0.1 \mathrm{~Hz}$ and a lowpass of $20 \mathrm{~Hz}$. The target stimulus (square) was selected as the trigger-stimulus. Epochs (i.e., visualization windows) were set to begin at the time of stimulus onset until 700 ms after. After specific channels were selected $(F z, C z$, and $\mathrm{Pz})$, data were averaged and represented graphically in terms of latency (x-axis) and amplitude (y-axis).

Component analysis - The P300 component was identified as the most positive component within the latency window of 250-500 ms. Amplitude was measured relative to a pre-stimulus baseline, with peak latency defined as the time point of maximum positive amplitude within the specific latency window.

Stroop test-The stroop test evaluates focused attention and assesses the integrative power of cognitive mechanisms in reaching decisions based upon information from two different modalities (lexical and perceptual ${ }^{20}$. First, the subjects were asked to read the name of a color and second, to name the printed color of a world denoting a different color (color-word interference). Subjects were asked to perform the task as quickly and as accurately as possible. The stroop color-naming task is a classic paradigm that elegantly illustrates important concepts such as automaticity and interference. The stroop paradigm has been in use for over half a century and has been described as the gold standard of attentional measures ${ }^{21}$. The criterion analyzed was raw score (number of correct answers).

Digit span test - The digit span test measures shortterm / working memory. Digit span forward and backward was performed according to the Wechsler adult intelligence scale administration instructions.

Reaction time - Reaction time was used as an index of individuals' motor performance. Volunteers responded to the target stimulus by pressing a button in a joystick. The joystick was used to measure individuals' reaction time at each trial. Missed stimuli were not considered. Although reaction time is independent from ERP measures, it was used to verify subjects' alertness during the task.
Statistical analysis - Different statistical analyses were performed in the present study. One-way Anova was performed for each behavioral measure (stroop, digit span, and reaction time) separately, across the three experimental conditions, i.e., B, P1, and P2. Three-way Anova, condition $x$ moment $x$ electrode $(3 \times 3 \times 4)$, was then performed for the electrophysiological measure, i.e., P300 latency and amplitude, in the Fz, Cz, Pz and Oz electrode sites separately. Post hoc (Scheffé) was applied a posteriori. Experimental moments were established as follows: 0' (before drug administration), 20' (twenty minutes after drug administration), and 60' (sixty minutes after drug administration).

\section{RESULTS}

Behavioral - Figure 1 illustrates stroop raw score variation across the three experimental conditions: B (105.93 \pm 12.64$),$ P1 (105.26 \pm 15.50$)$ and P2 $(102.93 \pm 26.14)$. The statistical analysis did not indicate any difference among the conditions ( $p=$ 0.902).

Figure 2 represents digit span score variation across the experimental conditions: $B(16.13 \pm 3.96)$, P1 (15.13 \pm 3.52$)$ and P2 (16.40 \pm 4.51$)$. The Anova did not reveal any difference across the conditions ( $p$ $=0.664)$.

Figure 3 expresses the variation in reaction time: B (395.24 $\pm 47.13 \mathrm{~ms})$, P1 (399.24 $\pm 43.41 \mathrm{~ms})$ and P2 (392.18 $\pm 42.07 \mathrm{~ms})$. No statistical significance was observed across the three groups $(p=0.296)$.

Electrophysiological - Figure 4 illustrates P300 latency $(A)$ and amplitude $(B)$ variations across conditions (B, P1, P2), moments $\left(0^{\prime}, 20^{\prime}, 60^{\prime}\right)$, and electrodes ( $\mathrm{Fz}, \mathrm{Cz}, \mathrm{Pz}, \mathrm{Oz})$. The three-way Anova revealed no interaction between moment and condition $(p=0.145)$, moment and electrode site $(p=$ $0.957)$, or condition and electrode site $(p=0.785)$ for latency. No main moment effects $(p=0.351)$ or condition effects $(p=0.652)$ were found. However, the analysis demonstrated a significant effect for electrode site $(p=0.000)$. The post hoc (Scheffé) analysis pointed out to the following differences: Fz$\mathrm{Pz}, \mathrm{Fz}-\mathrm{Oz}, \mathrm{Cz}-\mathrm{Pz}$ and $\mathrm{Cz}-\mathrm{Oz}(\mathrm{p}=0.000)$. In relation to amplitude values, the same pattern of results was observed. The three-way Anova revealed no interaction between moment and condition $(p=0.549)$, moment and electrode site $(p=0.993)$, or condition and electrode site $(p=0.999)$. No main moment e ffects $(p=0.301)$ or condition effects $(p=0.196)$ were found. However, there was a significant effect for electrode site $(p=0.000)$. The post hoc (Scheffé) indicated a difference between $\mathrm{Pz}$ and the other three electrode sites. 


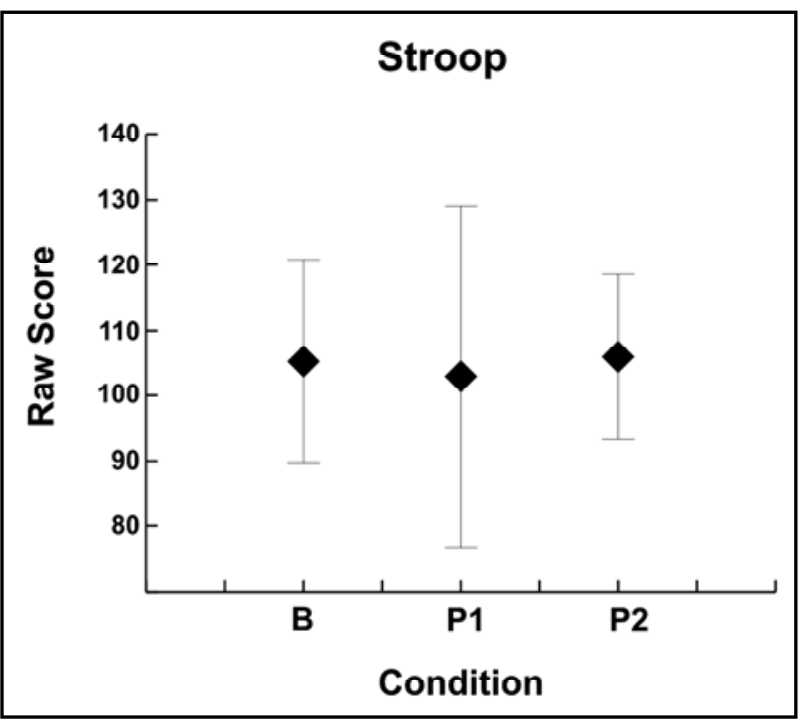

Fig 1. Stroop raw score variation across the bromazepam, place bo 1, and placebo 2 experiemental conditions.

\section{DISCUSSION}

The present study aimed at investigating the e ffects of bromazepam ( $3 \mathrm{mg}$ ) through behavioral and electrophysiological variables. Cognitive and motor responses were observed. The results were compared among conditions (placebos and bromazepam), moments (before, 20 and 60 minutes after drug intake) and cortical areas ( $\mathrm{Fz}, \mathrm{Cz}, \mathrm{Pz}$ and $\mathrm{Oz}$ ). The following discussion will be divided into three dependent variables, which were used to assess the effects of drug intervention: a) stroop and digit span; b) reaction time and c) P300 (latency and amplitude).

Stroop and digit span - Reports of stroop and digit span alterations after bromazepam administration are practically non-existent in current literature. More specifically, only two studies employed the digit span test and bromazepam combined. The first one, conducted by Liljequist et al. observed the effects of a two-week treatment with bromazepam and other benzodiazepines, alone or in combination with alcohol, on learning and memory, through the test ${ }^{22}$. It was observed that among the drugs, only bromazepam impaired learning significantly, and the combined effect of alcohol and bromazepam on learning capacity was very deleterious. The second study, by Hobi et al., observed the effects of bromazepam on psychomotor activity, attentiveness, and memory span ${ }^{23}$. Fifty-five healthy males, who received placebo, bromazepam $1.5 \mathrm{mg}$ and bromazepam $3 \mathrm{mg}$, were tested. In the attentiveness test, significant improvements in

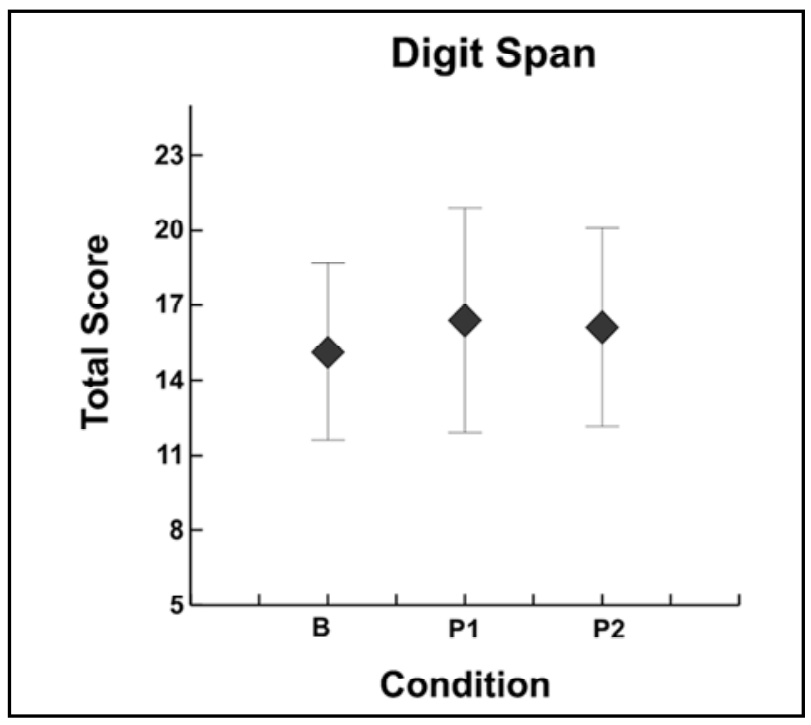

Fig 2. digit span score variation across the bromazepam, place bo 1 , and placebo 2 experimental conditions.

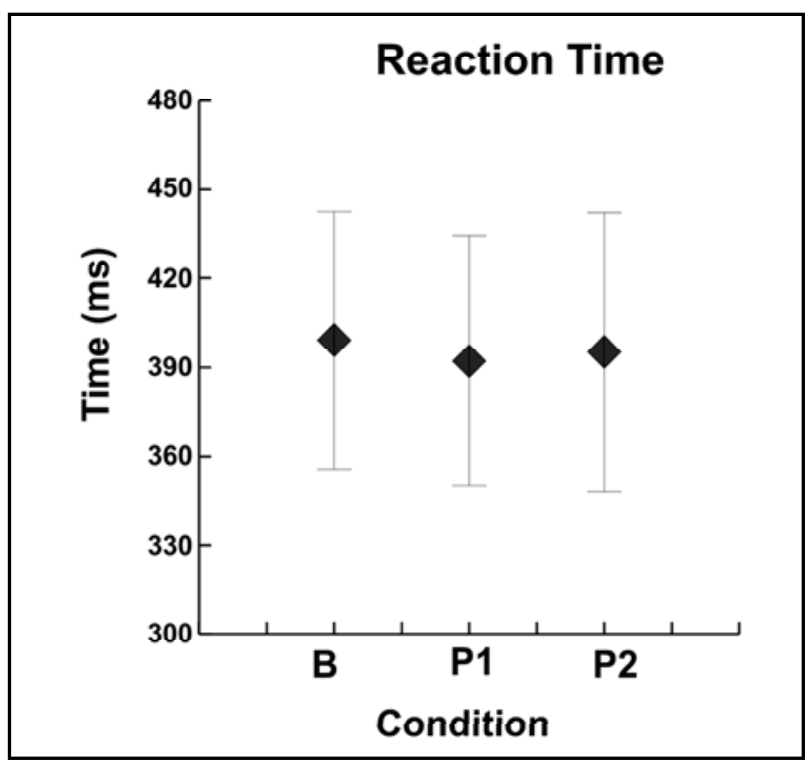

Fig 3. Reaction time variation across the bromazepam, place bo 1, and placebo 2 experimental conditions.

performance were observed in all three dosage groups. Memory span, too, improved slightly in the three groups. However, values for attentiveness and memory span did not seem to be affected by either dosage or drug. The authors concluded that subjects' attention and memory span were altered due to learning effects and not by bromazepam itself. Due to the lack of studies, results seem controversial on this issue.

On the other hand, experiments with stroop and digit span and other benzodiazepines, other than bromazepam, have been made. Griffiths et al. stu- 


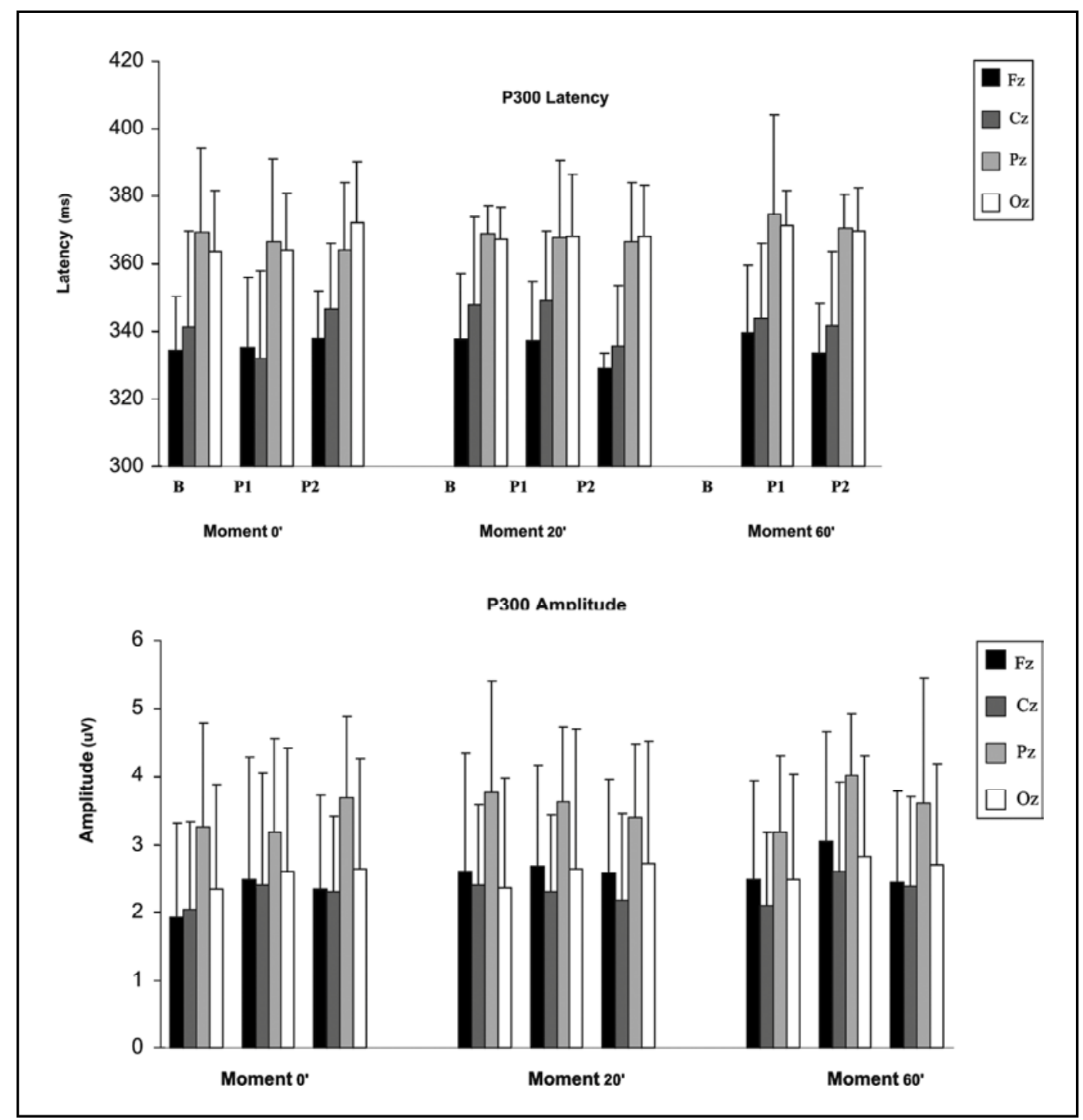

Fig 4. $P 300$ latency $(A)$ and amplitude $(B)$ variations across conditions $(B, P 1, P 2)$, moments $\left(0^{\prime}, 20^{\prime}, 60^{\prime}\right)$, and electrodes ( $F z, C z, P z, O z)$.

died cognitive function and psychomotor performance of 10 healthy male volunteers, subjected to oral doses of zopiclone ( $7.5 \mathrm{mg}$ ), flurazepam (15 $\mathrm{mg}$ ), lormetazepam (1 mg), triazolam $(0.25 \mathrm{mg}$ ) and placebo ${ }^{24}$. Stroop, reaction time, memory span were employed, among other tests. They demonstrated a clear reduction of performance for all active treatments. Matthews et al. observed the effects of single-dose lorazepam on memory and learning, and observed preservation of digit span scores $^{25}$. Thus, it is possible to note that the literature concerning the relationship between bromazepam, benzodiazepines, and attention and memory tests is still controversial.

Considering the existence of conflicting and ambiguous studies on this issue, as demonstrated above, and also the fact that the results of our experiment did not lead to any statistically significant changes, we can conclude that the results may be related to many other factors other than the drug studied, such as the dosage administrated, study design, and subjects' motivation.

Reaction time - Reaction time was assessed to analyze stimulus recognition, motor response and sensorimotor performance. It represents the time needed for someone to perceive and react to an external stimulus. Specifically, reaction time is the amount of time it takes a person to process an environmental (i.e., internal or external) signal. In a simple reaction time paradigm, we can respond to sensory stimuli delivered by different modalities, such as visual, auditory or somatosensory ${ }^{26}$. Some studies have analyzed the effects of bromazepam on 
reaction time. Jansen et al. examined the effects of bromazepam ( $6 \mathrm{mg}$ and $12 \mathrm{mg}$ ) on reaction time 65 minutes after drug administration, and observed decreased performance ${ }^{6}$. Bourin et al. investigated the effects of bromazepam $(3 \mathrm{mg})$ and other benzodiazepines on 20 healthy volunteers. Bromazepam effects were evaluated 2 and 6 hours after administration and no significant difference was shown 2 hours after drug ingestion. However, a longer motor reaction time was observed 6 hours after bromazepam ingestion? ${ }^{7}$ In another study, Hobi et al. observed a lengthening of reaction time for all three groups (placebo, bromazepam 1.5mg and bromazepam $3 \mathrm{mg}$ ), but concluded that this result was due to the type of experimental design used, and only slightly to the drug's action ${ }^{23}$. In our study, the effects of bromazepam (3mg) and placebo were observed 20 minutes and one hour after drug ingestion, and the statistical analysis did not indicate any difference across the conditions. In other words, we did not observe a lengthening of reaction time. Considering the results of the studies cited above, it can be concluded that the results may be influenced by the dosage administrated and time after drug administration that reaction time was measured. It may be possible that reaction time is not a sensitive measure to detect drug effects on the conditions described in the experiment.

P300 - Traditionally, the P300 component of the ERP is a cognitive neuroelectric event that expresses CNS ability to allocate attention and engage immediate memory during information processing. Recently, several findings have associated P300 variability with subjects' psychophysiological factors (e.g., arousal) ${ }^{16}$. To elucidate this issue, the present experiment addressed the modulatory effects of bromazepam in cognitive functions using the "oddball" paradigm.

Very few studies have combined bromazepam and event-related potentials. Studies employing this drug and the P300 component of the ERP are even scarcer. The only study available was done by Leeuwen et al., who tested thirty healthy females and analyzed the effects on event-related potentials through a visual vigilance task, 30 minutes after bromazepam ( 6 and $12 \mathrm{mg}$ ) administration. They observed smaller P300 amplitudes and shorter latencies ${ }^{9}$. A recent experiment with triazolam (a type of benzodiazepine) examined the effects of this drug on P300 and noted reduced P300 amplitudes mainly at PZ (parietal area) ${ }^{27}$. The same researchers investigated another type of benzodiaze- pine (brotizolam) and observed smaller P300 amplitudes on frontal regions (i.e., FZ electrode site) ${ }^{28}$.

The present study was designed to combine three different main factors, which were related to the effects of bromazepam on cognitive variables. The conjunction of drug intake (i.e. moment), experimental groups (i.e.conditions), and cortical areas (i.e., electrode sites) was previously established in the attempt to encompass possible sources of substance effects variability on brain neuroelectrical fluctuations. Previous experiments had not assessed the interaction of all three factors: moment, condition and scalp positions. We expected to find longer latencies in the bromazepam condition across the three distinct moments $\left(0^{\prime}, 20^{\prime}\right.$ and $\left.60^{\prime}\right)$, due to the drug's GABA enhancement property. GABA is the major inhibitory neurotransmitter and benzodiazepines improve GABA activity in different CNS areas. In this sense, we also expected to find shorter amplitudes in the bromazepam condition. In other words, we expected an impaired cognitive functioning.

Our study observed P300 latency and amplitude variations across conditions ( $\mathrm{B}, \mathrm{P} 1, \mathrm{P} 2)$, moments $\left(0^{\prime}, 20^{\prime}, 60^{\prime}\right)$, and electrodes ( $\mathrm{Fz}, \mathrm{Cz}, \mathrm{Pz}$ and $\left.\mathrm{Oz}\right)$. However, our results showed no interaction among these factors, and only one main effect for electrode. This finding can be explained by the fact that the pattern of amplitude and latency distribution across different electrodes occurs independently from others variants (i.e., conditions and moments). Such findings suggest that the effects of bromazepam dosage used in our experiment (i.e., $3 \mathrm{mg}$ ), may not cause differences on cognitive processes assessed by ERP measures. Future studies are necessary to particularly elucidate this issue.

In terms of the drug's anxiolytic action, it appears that bromazepam can exert a positive effect on psychomotor performance ${ }^{23}$. In our study, anxiety was not assessed through psychometric scales. In this regard, it is possible that the sample was not entirely homogeneous. Thus, individual anxiety states should be considered as a possible source of variability. In addition, the time of day that subjects were tested may also have influenced the results. All subjects were tested between 10:00am and 4:00pm. If the experiment had been carried out at late hours (e.g., 10:00pm), results might have been different due to physiological fluctuations (e.g., fatigue). Finally, considering that bromazepam has a half-life of 8-20 hours and its plasma concentra- 
tion peak occurs approximately 1 hour after its oral administration ${ }^{29}$, results might have been influenced by the time interval between drug ingestion and the testing. In this sense, longer intervals might yield different results.

Further studies, using different doses of bromazepam and analyzing its acute and subacute effects, are necessary to truly understand the effects of this benzodiazepine on cognitive and motor performance, as well as in brain dynamics and information processing.

\section{REFERENCES}

1. Graeff FG. Drogas psicotrópicas e seu modo de ação. 2.Ed. São Paulo: EPU, 1989.

2. Katzung BG. Basic clinical pharmacology. 6.Ed. London: Pretence-Hall International, 1995.

3. Oelschlager $\mathrm{H}$. Chemical and pharmacologic aspects of benzodiazepines Schweiz Rundsch Med Prax 1989;78:766-772.

4. Kopp C, Rudolph U, Low K, Tobler I. Modulation of rhythmic brain activity by diazepam: GABA(A) receptor subtype and state specificity. Proc Natl Acad Sci USA 2004;101:3674-3679.

5. Hobi V, Dubach UC, Skreta M, Forgo I, Riggenbach H. The subacute effect of bromazepam on psychomotor activity and subjective mood. J Intern Med Res 1982;10:140-146.

6. Jansen AAI, Verbaten MN, Slangen JL. Acute effects of bromazepam on signal dection performance digit symbol substitution test and smooth pursuit eye movements. Neuropsychobiology 1988;20:91-95.

7. Bourin M, Auget JL, Colombel MC, Larousse C. Effects of single oral doses of bromazepam, buspirone and clobazam on performance tasks and memory. Pharmacopsychiatry 1989;22:141-145.

8. Koelega HS. Benzodiazepines and vigilance performance : a review. Psychopharmacology 1989;98:145-156.

9. Leeuwen van TH, Verbaten MN, Koelega HS, Kenemans JL, Slangen JL. Effects of bromazepam on single-trial event-related potentials in a visual vigilante task. Psychopharmacology 1992;106:555-564.

10. Halgren E, Marinkovic K, Chauvel P.Generators of the late cognitive potentials in auditory and visual oddball tasks. Electroencephalogr Clin Neurophysiol 1998;106:156-164.

11. Pfurtscheller G, Neuper C. Motor imagery activates primary sensorimotor area in humans. Neurosci Lett 1997;239:65-68.
12. Babilone C, Babilone F, Carducci F, Cincotti F. Human moviment-related potentials vs desynchonization of EEG alpha rhythm: a high-resolution EEG study. Neuroimage 1999;10:658-665.

13. Pang E, Fowler B. Descriminating the effects of triazolam on stimulus and response processing by means of reaction time and P300 latency. Psychopharmacology 1994;115:509-515.

14. Koelega HS, Verbatin MN. Event-related brain potentials and vigilance brain performance: dissociations abound: a review. Percep Motor Skills 1991;72:971-982.

15. Ortiz T, Maestú F, Lopez-Ibor JJ. Origen, significado cognitivo y aplicaciones clínicas en psiquiatria del componente P300. Actas Luso Esp Neurol Psiquiatr Cienc Afines 1998;26:315-332.

16. Polich J. P300 in clinical applications. In Niedermeyer E, Lopes da Silva F (eds). Electroencephalography: basic principles, clinical applications and related fields. 4.Ed. Baltimore: Urban \& Schwarzenberg, 1999:1073-1091.

17. Ortiz A, Perez-Serrano J, Zaglug C, Coullaut J, Coullaut R, Criado J. P300 clinical utility in major depression. Actas Esp Psiquiatr 2002;30:1-6.

18. Polich J. P300 clinical utility and control of variability. J Clin Neurophysiol 1998;15:14-33.

19. Jasper H. The ten-twenty electrode system of the international federation. EEG Clin Neurophysiol 1958;10:371-375.

20. Graeff FG, Parente A, Del-Ben CM, Guimarães FS. Pharmacology of human experimental anxiety. Braz J Med Biol Res 2003;36:421-432.

21. Edward S, Brice C, Craig C, Penri-Jones R. Effects of caffeine, practice, and mode of presentation on stroop task performance. Pharmacol Bioch Behav 1996;54:309-315.

22. Liljequist R, Linnoila M, Mattila MJ, Saario I, Seppala T. Effect of two weeks treatment with thioridazine, chlorpromazine, sulpiride and bromazepam, alone or in combination with alcohol, on learning and memory in man. Psychopharmacologia 1975;44:205-208.

23. Hobi V, Dubach UC, Skreta M, Forgo J, Riggenbach H. The effect of bromazepam on psychomotor activity and subjective mood. J Int Med Res 1981;9:89-97.

24. Griffiths AN, Jones DM, Richens A. Zopiclone produces effects on human performance similar to flurazepam, lormetazepam and triazolam. Br J Clin Pharmacol 1986;21:647-653.

25. Matthews A, Kirkby KC, Martin F. The effects of single-dose lorazepam on memory and behavioural learning. J Psychopharmacol 2002;16:345-354.

26. Kandel E, Schwartz S, Jessel T. Principles of neuroscience. 4.Ed. New York: McGraw-Hill, 2000.

27. Hayakawa T, Uchiyama M, Urata J. Effects of small dose of triazolam on P300. Psychiatry Clin Neurosci 1999;53:185-187.

28. Hayakawa T, Uchiyama M, Enomoto T. Effects of small dose of brotizolam on P300. Pharmacology 2000;54:319-320.

29. Kaplan SA, Jack ML, Weinfeld RE, Glover W, Weissman L, Cotler S. Biopharmaceutical and clinical pharmacokinetic profile of bromazepam. J Pharmacokin Biopharmac 1976;4:1. 